\title{
Dependence of Company Size on Factors Influencing Bankruptcy
}

\author{
Martina Sponerova ${ }^{1, *}$, Miroslav Sponer $^{2}$, and Miroslav Svoboda ${ }^{1}$ \\ ${ }^{1}$ Masaryk University, Faculty of Economics and Administration, Department of Finance, Lipova 41a, \\ 60200 Brno, Czech Republic \\ ${ }^{2}$ Czech Technical University in Prague, Masaryk Institute of Advanced Studies, Kolejní 2637/2a, \\ 16000 Prague 6, Czech Republic
}

\begin{abstract}
.
Research background: There is extensive empirical literature on default prediction methodologies. Many authors during the last fifty years have examined several possibilities to predict default or business failure. The reviews from the last years show that the closer the similarity of businesses, the greater accuracy of bankruptcy models.

Purpose of the article: The aim of this article is finding if there exist different factors that could predict bankruptcy depending on the size of the company. Our motivation is to show if there exist differences when predicting bankruptcy according the size of the company.

Methods: This paper focuses on the Czech economy, specifically at small and medium sized enterprises (SMEs). It is the ongoing research about the value of several popular bankruptcy models that are often applied, namely the Altman Z-score, the Ohlson O-score, the Zmijewski's model, the Taffler's model, and the IN05 model. We have used logistic regression and investigated around 2800 companies, of which 642 failed during the period $2010-2017$.

Findings \& Value added: Results of the analysis confirm research hypotheses that there exist different factors which could predict bankruptcy depending on the size of the company and exploit common used financial indicators to assess the probability of bankruptcy precisely. We have found that for the segment of micro-enterprises is necessary to pay attention to liquidity and profitability. Small enterprises emphasize to leverage, liquidity and profitability while the model developed for the segment of mediumsized enterprises measures most of all leverage, liquidity and activity.
\end{abstract}

Keywords: credit risk; bankruptcy prediction; SME; financial indicator

JEL Classification: $G 32$; $G 33$; $C 53$

\footnotetext{
* Corresponding author: martina.sponerova@econ.muni.cz
} 


\section{Introduction}

The prediction of bankruptcy and the quantification of credit risk is the subject of interest of many studies, scientific articles and publications. The ability to predict the bankruptcy is the factor, which eliminates credit risk of a bank. Academics and practitioners have focused their research to improve the performance of existing bankruptcy models and they are still developing new models and methods to precisely predict business failure. The abundance of bankruptcy prediction models gives rise to the idea that these models are not in compliance with the changing business conditions in the market and do not meet the increasing complexity of business tasks.

Business failure is closely connected with credit risk, which is one of the most significant risks of financial institutions. Hence, there is pressure on financial institutions to improve their credit risk management systems still to predict bankruptcy as accurately as possible.

The aim of this article is finding if there exist different factors that could predict bankruptcy depending on the size of the company and compare the differences. Considering the research objective, the following hypotheses were set: H1: The usually used financial indicators in financial analysis are the most important for bankruptcy prediction.; H2: The application of a model created on the grounds of company size improves the reliability of bankruptcy prediction.

This paper focuses on SMEs because they are reasonably considered as the most important segment of the economy in many countries. For OECD members, the percentage of SMEs out of the total number of firms is higher than 97\%. SMEs employ approximately two-third of employees and create more than half of the added value in EU-28 [1]. Thanks to their simple structure, they can respond quickly to changing economic conditions and meet local customers' needs, growing sometimes into large and powerful corporations or failing within a short time of the firm's inception.

We have decided to reach as accurate as possible results to split our database into three groups respecting the size of companies to micro-enterprises, small enterprises and mediumsized enterprises. The micro-enterprises are very new, beginning companies, without stable contracts with partners, but with significant potential to grow. On the other hand, they face many different risks. The small enterprises are relatively stable, established companies, with a potential to grow, still facing bankruptcy risk. The medium-sized companies are stable, established, with low potential to growth and low probability of bankruptcy.

After performing the analysis of scientific literature, we identified that various scientists who have studied bankruptcy prediction models under different perspectives still could not indicate the most reliable model as it can be observed by brief preview to the history.

Many authors during the last fifty years have examined several possibilities to predict default or business failure. The seminal works in this field were Beaver in 1967 and Altman in 1968. The researcher William Beaver was the first to apply several ratios, which could discriminate between failed and non-failed companies up to five years before the bankruptcy. Altman improved Beaver's method and assessed a more complete financial profile of firms. Altman examines 22 potentially helpful financial ratios and selects five that provide, when combined, the best overall prediction of corporate bankruptcy. The variables are classified into five standard ratio categories - liquidity, profitability, financial leverage, activity and solvency. Being the first person to successfully develop multiple discriminate analysis (MDA) prediction model with a degree of $95.0 \%$ rate of accuracy, he is considered the pioneer of insolvency predictors. Altman's model has been applied successfully in many studies worldwide concerning the subjects of capital structure and strategic management, investment decisions, asset and credit risk estimation and financial failure of publicly traded companies [2]. 
For many years thereafter, MDA was the prevalent method applied to the default prediction models. It was used by many authors for example very often cited in the research literature is Taffler model developed in Great Britain in 1977 [3]. However, in most of these studies, authors pointed out, that two basic assumptions of MDA are often violated - the independent variables included in the model are multivariate normally distributed; the group of variance-covariance matrices are equal across the failing and non-failing group [4].

Inka and Ivan Neumaier have developed another MDA model in 1995 known as IN95. This model was constructed especially for the Czech market and was updated in the next years. We use the last version - IN05 model, which was developed in 2005 [5].

Considering these MDAs' problems, Ohlson in 1980 [6], for the first time, applied the conditional logit model to the default prediction's study. The practical benefits of logit methodology are that they do not require the restrictive assumptions of MDA and allow working with disproportional samples. After Ohlson, most of the academic literature used logit models to predict default. Next, very often cited model, which uses conditional probability, is a model by Mark E. Zmijewski [7]. He was the pioneer in applying probit analysis to predict default but, until now, logit analysis has given better results in this field. A probit approach is the same as in the logit approach, different is only the distribution of random variables.

As Waqas and Md-Rus [8] research shows, almost all bankruptcy research is based on financial indicators, as are the majority of traditional models. Meanwhile, non-financial variables are rarely used and constitute a minority of all research on bankruptcy prediction according to Lawrence et al. [9]

Grunert et al. [10] also highlight the significance of qualitative information such as business type, industrial sector, location, age, and more in the understanding of firms' credit risk behaviour. Altman et al. [11] took account this issue and studied about 5.8 million SMEs, of which 66000 failed during the observed period $2000-2007$. They reported that the prediction performance of Altman and Sabato model from 2007 improved by about 13\% when qualitative information is added. They found that data relating to legal action by creditors to recover unpaid debts, company filing histories, comprehensive audit report/opinion data and firm-specific characteristics make a significant contribution to increasing the default prediction power of risk models built specifically for SMEs.

From the recent literature, we can mention Tomczak and Radosinski [12]. They highlight that the increase in the number of indicators used in the model probably has no positive impact on its total results. The most effective models are based on three or five indicators $[12,13]$. On the other hand, the worst models cover six to eight indicators. It is worth mentioning that the most effective models are those that are specially developed and adapted for a specific economic sector $[14,15]$. This statement could be similar to our hypothesis that the application of a model created on the grounds of company size improves the reliability of bankruptcy prediction. The greater the similarity of the selected companies, the more accurate is the prediction of bankruptcy.

We witness a substantial increase in the number and complexity of default prediction studies due to the rapid advancement in technology and methodology. Above all, we can mention artificial neuron networks used by Angelini et al. [16], decision trees method used by Gulnur and Fikret [17] and hazard models used by Shumway [18]. Some scientists $[19,20,14]$ claim that company insolvency information retrieved by artificial neural networks is superior to the information obtained when applying traditional statistical models. According to Alaka et al. [21], although traditional statistical models based on discriminant analysis are not completely precise when compared to non-linear complex artificial intelligence methods. Due to their simple calculation and accuracy, they are much simpler and more efficient than artificial intelligence models. However, Glezakos et al. [22] present a different evaluation and claim that logistic regression models are amongst the most efficient 
ones. The analyzed scientific research proves contrary to opinions regarding neural network models' applicability when identifying companies' bankruptcies.

Meanwhile, other authors $[23,24]$ saw a contrary phenomenon and suggest that the application of neural networks model alone reduces the accuracy of predictions. Besides, alternative models are difficult to apply due to their complexity and difficulty, and these models require broad databases and time resources. Often these models have to be integrated and adapted to a specific company.

Assessing the performed analysis of the alternative bankruptcy prediction models, we can state that their application in scientific research is becoming increasingly popular. However, due to the models being challenging to adapt to companies, it is unlikely that they will be applied in practice. In order to make a more precise prediction of a company's bankruptcy likelihood, it is reasonable to apply several models or to adapt one model according to the company's internal and external environments, area of activity, size and the like.

\section{Methodology and Data}

Our dataset consists of a sample of 2799 SMEs that survived in the period $2010-2017$ out of which 638 companies failed in this period time. This data was exclusively gained from a bank database by a random selection of SMEs that survived and all of SMEs that failed during the above mentioned period. The dataset was sorted out first, so the final number of the sample is then really 2799 SMEs from the original 6381 SMEs.

In our previous research, we have compared the prediction power of the bankruptcy models, which are used very often in many scientific papers - the Altman's Z-score, the Ohlson's O-score, the Zmijewski's model, the Taffler's model, and the IN05 model. We found that the performance of these models reached from $69 \%$ to $55 \%$. Next step in our research was determined to re-estimate coefficients for analyzed companies and develop a new model, which should provide the best possible results. [27]

\subsection{Dataset}

We have decided to reach as accurate as possible results to split our database into three groups respecting the size of companies. These groups represent a distribution of SMEs according to Commission Regulation (EC) No 800/2008 into micro-enterprises, small enterprises and medium-sized enterprises.

The category of micro, small and medium-sized enterprise is made up as enterprises which employ fewer than 250 persons and which have an annual turnover not exceeding EUR 50 million, and/or annual balance sheet total does not exceed EUR 43 million.

The micro-enterprise is defined as an enterprise which employs fewer than 10 persons and whose annual turnover and/or annual balance sheet total does not exceed EUR 2 million.

The small enterprise is defined as an enterprise which employs fewer than 50 persons and whose annual turnover and/or annual balance sheet total does not exceed EUR 10 million.

According to a study by W. H. Beaver, the bankruptcy of a company could be predicted up to 5 years in advance. Altman's studies prove that the best models are with a prediction of 1 to 2 years in advance. So, we kept from the database of bankrupt companies only statements of companies one year before bankruptcy. As a bankrupt company, we consider companies in real bankrupt or companies in liquidation according to Czech law.

Sorting of our database according to criteria is mentioned in Table 1. 
Table 1. Database sorting.

\begin{tabular}{|c|c|c|c|}
\hline Size & Healthy & Bankrupt & Total \\
\hline Micro-enterprises & 764 & 229 & 993 \\
\hline Small enterprises & 704 & 220 & 924 \\
\hline Medium-sized enterprises & 693 & 189 & 882 \\
\hline Total SMEs & 2161 & 638 & 2799 \\
\hline
\end{tabular}

We used sixteen financial indicators see Table 2. We took the variables from the models, which are used in Altman's Z-score, the Ohlson's O-score, the Zmijewski's model, the Taffler's model, and the IN05 model as we have compared the prediction power of these models in our previous research. They measure most of all leverage and profitability as it can be seen in Table 2 .

Table 2. List of financial indicators.

\begin{tabular}{|c|c|c|}
\hline Group & Coding & Formula \\
\hline \multirow{9}{*}{ Leverage } & L003 & equity/liabilities \\
\hline & L006 & current assets/liabilities \\
\hline & L007 & short-term payables/total assets \\
\hline & L008 & total assets/liabilities \\
\hline & L010 & short-term liabilities/current assets \\
\hline & L012 & liabilities/equity \\
\hline & L013 & liabilities/total assets \\
\hline & L015 & equity/long-term assets \\
\hline & L016 & $\begin{array}{l}\text { equity }+ \text { reserves }+ \text { long-term } \\
\text { liabilities/long-term assets }\end{array}$ \\
\hline \multirow{2}{*}{ Liquidity } & I001 & working capital/total assets \\
\hline & $\mathrm{I} 004$ & sales/total assets \\
\hline \multirow{4}{*}{ Profitability } & P002 & retained earnings/total assets \\
\hline & P005 & EBT/short-term liabilities \\
\hline & P009 & EBIT/interest cost \\
\hline & P011 & EAT/total assets \\
\hline Activity & A014 & current assets/short-term liabilities \\
\hline
\end{tabular}

Most of these indicators are not often used in financial analysis; they have been used in known bankruptcy models which we have examined in our previous research. 


\subsection{Model Specification}

Logistic regression is the appropriate regression analysis to conduct when the dependent variable is dichotomous (binary). Like all regression analyses, the logistic regression is a predictive analysis. Logistic regression is used to describe data and to explain the relationship between one dependent binary variable and one or more nominal, ordinal, interval or ratio-level independent variables. The dependent variable should be dichotomous in nature (e.g. in our case bankrupt or non-bankrupt companies). There should be no outliers in the data, no high correlations (multicollinearity) among the predictors. Mathematically, logistic regression estimates a multiple linear regression function defined as:

$$
\pi(x)=\frac{\exp ^{\left(\alpha+\beta_{1} X_{1}+\beta_{2} X_{2}+\beta_{3} X_{3}+\cdots \beta_{n} X_{n}\right)}}{1+\exp ^{\left(\alpha+\beta_{1} X_{1}+\beta_{2} X_{2}+\beta_{3} X_{3}+\cdots \beta_{n} X_{n}\right)}}
$$

The expression $\pi(x)$ is called logit. The values of $\alpha$ and $\beta$ are regression coefficients. The iterative least-squares method is used to estimate $a, b$. This method is used to obtain a maximum of plausible estimates of $\alpha$ and $b$. The logistic regression model can be expressed by a sigmoidal curve expressing $\pi(x)$ estimation of the dependence of the probability of occurrence of the observed phenomenon depending on $x$. This model can then be used to predict probability or risk at set values of $x . X$ is independent variable, in our case is multidimensional, $x=\left(x_{1}, \ldots, x_{n}\right)$.

\section{Results and Discussion}

We have tested each group and all the dataset separately. We test the null hypothesis, which means that the explanatory variables do not affect the explained variable. The parameter $\beta$ is set at the level of 0,10 , which means that we are talking about statistical significance at the level of $10 \%$. We have used the backward method in IBM SPSS sofware.

The results are mentioned in Tables $3-7$. Variables mentioned in Table 2 entered into logistic regression with the below-mentioned result.

Table 3. Variables predicting bankruptcy for micro-enterprises.

\begin{tabular}{|c|c|c|}
\hline Coding & Coefficient B & p-value \\
\hline Constant & $-2,932$ & 0,000 \\
\hline A004 & 0,071 & 0,000 \\
\hline L007 & 0,845 & 0,081 \\
\hline L013 & 0,022 & 0,001 \\
\hline L015 & 0,006 & 0,054 \\
\hline P002 & $-1,532$ & 0,006 \\
\hline P009 & $-0,002$ & 0,065 \\
\hline P011 & $-1,607$ & 0,095 \\
\hline
\end{tabular}

The model developed for the segment of micro-enterprises shows that it is necessary to pay attention to many factors of a company's financial situation. We can say that all significant indicators are usual indicators of bankruptcy. It measures most of all, leverage 
and profitability. Even Tomczak and Radosinski [13] and Karas and Reznakova [14] state in their researches that the worst models are that with six or eight indicators, the predictability of the model for micro-enterprises reached $77,5 \%$.

Table 4. Variables predicting bankruptcy for small enterprises.

\begin{tabular}{|c|c|c|}
\hline Coding & Coefficient B & p-value \\
\hline Constant & $-1,891$ & 0,001 \\
\hline I014 & $-0,449$ & 0,004 \\
\hline L007 & 1,217 & 0,042 \\
\hline L013 & 0,023 & 0,001 \\
\hline P002 & $-2,002$ & 0,002 \\
\hline
\end{tabular}

Surprisingly, the model developed for the segment of small enterprises has fewer indicators and measures most of all, leverage. The predictability of the model for small enterprises reached $78,9 \%$.

Table 5. Variables predicting bankruptcy for medium-sized enterprises.

\begin{tabular}{|c|c|c|}
\hline Coding & Coefficient B & p-value \\
\hline Constant & $-1,891$ & 0,001 \\
\hline I001 & 2,308 & 0,001 \\
\hline I014 & $-0,247$ & 0,006 \\
\hline L008 & 0,120 & 0,003 \\
\hline L013 & 0,046 & 0,000 \\
\hline L016 & 0,059 & 0,014 \\
\hline I001 & 2,308 & 0,001 \\
\hline
\end{tabular}

The model developed for the segment of medium-sized enterprises has six indicators and measures, most of all, leverage. Even this model has six indicators; the model for mediumsized enterprises reached the highest predictability $79,8 \%$.

Table 6. Variables predicting bankruptcy for the whole dataset.

\begin{tabular}{|c|c|c|}
\hline Coding & Coefficient B & p-value \\
\hline Constant & $-2,612$ & 0,000 \\
\hline A004 & 0,029 & 0,020 \\
\hline I014 & $-0,178$ & 0,001 \\
\hline L003 & 0,101 & 0,001 \\
\hline
\end{tabular}




\begin{tabular}{|c|c|c|}
\hline L013 & 0,029 & 0,000 \\
\hline L015 & 0,009 & 0,001 \\
\hline P002 & $-1,197$ & 0,000 \\
\hline P011 & $-1,123$ & 0,038 \\
\hline
\end{tabular}

The result if we do not distinguish the size of the company is a mixture of all previous models. It measures most of the leverage again. The predictability of the model for all data reached $77,2 \%$, which is the lowest predictability. The result confirms our hypothesis $\mathrm{H} 2$ when we develop a bankruptcy model; it is necessary to sort companies according to size.

Table 7. Variables predicting bankruptcy for the whole dataset.

\begin{tabular}{|c|c|c|c|c|c|}
\hline Group & Coding & $\begin{array}{c}\text { Micro- } \\
\text { enterprises }\end{array}$ & $\begin{array}{c}\text { Small } \\
\text { enterprises }\end{array}$ & $\begin{array}{c}\text { Medium-sized } \\
\text { enterprises }\end{array}$ & $\begin{array}{c}\text { Total } \\
\text { SMEs } \\
\end{array}$ \\
\hline & Constant & $-2,932$ & $-1,891$ & $-3,498$ & $-2,612$ \\
\hline \multirow{9}{*}{ Leverage } & L003 & & & & 0,101 \\
\hline & L006 & & & & \\
\hline & L007 & 0,845 & 1,217 & & \\
\hline & L008 & & & 0,120 & \\
\hline & L010 & & & & \\
\hline & L012 & & & & \\
\hline & L013 & 0,022 & 0,023 & 0,046 & 0,029 \\
\hline & L015 & 0,006 & & & 0,009 \\
\hline & L016 & & & 0,059 & \\
\hline \multirow{2}{*}{ Liquidity } & I001 & & & 2,308 & \\
\hline & I014 & & 0,449 & $-0,247$ & $-0,178$ \\
\hline \multirow{4}{*}{ Profitability } & P002 & $-1,532$ & $-2,002$ & & $-1,197$ \\
\hline & P005 & & & & \\
\hline & P009 & $-0,002$ & & & \\
\hline & P011 & $-1,607$ & & & $-1,123$ \\
\hline Activity & A004 & 0,071 & & $-0,372$ & 0,029 \\
\hline $\begin{array}{c}\text { Categorisation } \\
\text { rate }\end{array}$ & & $77,5 \%$ & $78,9 \%$ & $79,8 \%$ & $77,2 \%$ \\
\hline
\end{tabular}


The total comparison shows that when we assess micro-enterprises, we have to focus on leverage and profitability while small enterprises could have problems with leverage, profitability and liquidity. When assessing the financial situation of the medium-sized enterprises, we have to focus on leverage, liquidity and activity. The most important indicators are these which are used very often when analyzing a company's financial situation. They are indebtedness like indicator L013, current liquidity like indicator I014, a little modification of ROA like indicator P002 and ROS like indicator A004. It confirms our hypothesis $\mathrm{H} 1$ that usually used financial indicators are the best one, and it is not necessary to devise any other indicator.

\section{Conclusions}

This study analyzed if there are various factors to predict bankruptcy for different size of Czech SME's. We have investigated financial data for the years from 2010 to 2017. The whole dataset was divided into three groups - micro-enterprises, small enterprises and medium-sized enterprises. The analyses were done separately for each group and for the whole dataset to capture different characteristics of companies with a different size. We used sixteen financial indicators. We took the variables from the models, which are used in Altman's Z-score, the Ohlson's O-score, the Zmijewski's model, the Taffler's model, and the IN05 model as we have compared the prediction power of these models in our previous research. Most of these indicators are not often used in financial analysis.

We have found that when we assess micro-enterprises, we have to focus on leverage and profitability while small enterprises could have problems with leverage, profitability and liquidity. When assessing the financial situation of the medium-sized enterprises, we have to focus on leverage, liquidity and activity. The most critical indicators are these which are used very often when analyzing a company's financial situation. They are indebtedness like indicator L013, current liquidity like indicator I014, a little modification of ROA like indicator P002 and ROS like indicator A004. It confirms our hypothesis H1 that usually used financial indicators are the best one, and it is not necessary to devise any other indicator.

Our findings confirm our hypothesis, and some suggestion arises from it. When we develop a bankruptcy model, it is necessary to sort companies according to size and exploit common used financial indicators to assess the probability of bankruptcy precisely.

The support of the Masaryk University internal grant MUNI/A/1081/2019 - Predikce rizik na vybraných finančních trzích is gratefully acknowledged.

\section{References}

1. European SME Week 2017. (2017, November 21). SMEs in the European Union generate half of the intra-EU trade in goods. Eurostat. Retrieved from: https://ec.europa.eu/eurostat/documents/2995521/8467294/6-21112017-APEN.pdf/ab123dd2-0901-4c64-95b0-f071a5f235e3

2. Lifschutz, S., Jacobi, A. (2010). Predicting Bankruptcy: Evidence from Israel. International Journal of Business and Management, 5(4), 133-141.

3. Taffler, R., Tishaw, H. (1977). Going, going, gone - four factors which predict. Accountancy, 3, 50-54.

4. Barnes, P. (1982). Methodological implications of non-normality distributed financial ratios. Journal of Business Finance and Accounting, 9, 51-62. 
5. Neumaierová, I., Neumaier, I. (2005). Index IN05. In J. Krajíček \& V. Kajurová (Eds.), European Financial Systems 2015: Proceedings of the 12th International Scientific Conference (pp. 143-146). Brno: Masaryk University.

6. Ohlson, J. A. (1980). Financial ratios and the probabilistic prediction of bankruptcy. Journal of Accounting Research, 18(1), 109-131.

7. Zmijewski, M. (1984). Methodological issues related to the estimation of financial distress prediction models. Journal of Accounting Research, 22, 59-82.

8. Waqas, H., Rohani M.-R. (2018). Predicting financial distress: Applicability of O-score and logit model for Pakistani firms. Business and Economic Horizons, 14(2), 389-401.

9. Lawrence, J. R., Pongsatat S., Lawrence H. (2015). The use of Ohlson's O-Score for bankruptcy prediction in Thailand. Journal of Applied Business Research 31(6), 20692078.

10. Grunert J., Norden L., Weber M. (2005). The role of non-financial factors in internal credit ratings. Journal of Banking \& Finance, 29(2), 509-531.

11. Altman E. I., Sabato G., Wilson N. (2010). The value of non-financial information in small and medium-sized enterprise risk management. The Journal of Credit Risk, 6(2), $1-33$.

12. Tomczak, S. K., Radosinski E. (2017). The effectiveness of discriminant models based on the example of the manufacturing sector. Operations Research and Decisions, 27(3), 8197.

13. Karas, M., Reznakova M. (2017). Predicting the bankruptcy of construction companies: A CART-based model. Engineering Economics, 28(2), 145-154.

14. Barbuta-Misu, N., Codreanu E. S. (2014). Analysis and prediction of the bankruptcy risk in Romanian building sector companies. Ekonomika, 93(2), 131-146.

15. Fedorova, E. A., Dovzhenko S. E., Fedorov F. Y. (2016). Bankruptcy-prediction models for Russian enterprises: Specific sector-related characteristics. Studies on Russian Economic Development, 27, 254-261.

16. Angelini, E., Tollo Di., G., Roli, A. (2007). A neural network approach for credit risk evaluation. The Quarterly Review of Economics and Finance, 48(4), 733-755.

17. Gulnur, D., Fikret. G. (2011). Knowledge discovery using neural approach for SME's credit risk analysis problem in Turkey. Expert Systems with Applications, 38(8), 93139318.

18. Shumway, T. (2001). Forecasting bankruptcy more accurately: A simple hazard model. Journal of Business, 74(1), 101-124.

19. Zieba, M., Tomczak S. K., Tomczak J. M. (2016). Ensemble boosted trees with synthetic features generation in application to bankruptcy prediction. Expert Systems with Applications, 58, 93-101.

20. Belas, J., Misankova M., Schonfeld J., Gavurova B. (2017). Credit risk management: financial safety and sustainability aspects. Journal of Security and Sustainability Issues, 7(1), 79-93.

21. Alaka, H. A., Oyedele L. O., Owolabi H. A., Kumar V., Ajayi S. O., Akinade O. O., Bilal M. (2018). Systematic review of bankruptcy prediction models: Towards a framework for tool selection. Expert Systems with Applications, 94, 164-184.

22. Glezakos, M., Mylonakis J., Oikonomou K. (2010). An empirical research on early bankruptcy forecasting models: Does logit analysis enhance business failure predictability? European Journal of Finance \& Banking Research, 3(3), 1-15. 
23. Abdipoor, S., Nasseri A., Mojtaba Akbarpour, Parsian H., Zamani S. (2013). Integrating neural network and colonial competitive algorithm: A new approach for predicting bankruptcy in Tehran security exchange. Asian Economic and Financial Review, 3(1), 1528-1539.

24. Bredart, X. (2014). Bankruptcy prediction model using neural networks. Accounting and Finance Research, 3(2), 124-128.

25. Plíhal, T., Sponerová, M., Sponer, M. (2018). Comparative Analysis of Credit Risk Models in Relation to SME Segment. Financial Assets and Investing, 9(1), 35-50. 